\title{
Relationship of Polymorphisms of Glutathione S-Transferase GSTT1 and GSTM1 with the Response to Chemotherapy in Mexican Women with Advanced Breast Cancer
}

\author{
Odeth Soto-Quintana ${ }^{1}$, Paula Cabrera-Galeana ${ }^{2}$, Gabriel Téllez-Trevilla ${ }^{2}$, José Luis Barrera-Franco ${ }^{2}$, \\ Alejandro Juárez-Ramiro ${ }^{3}$, Julieta Castillo-Cadena ${ }^{1^{*}}$ \\ ${ }^{1}$ Laboratorio de Genética, Facultad de Química Universidad Autónoma del Estado de México, Toluca, México; ${ }^{2}$ Centro Oncológico \\ Estatal ISSEMyM, Toluca, México; ${ }^{3}$ Hospital de la Mujer, Miguel Hidalgo, México. \\ Email: jcastillo_cadena@hotmail.com
}

Received May 23 ${ }^{\text {rd }}, 2011$; revised June 29 ${ }^{\text {th }}, 2011$; accepted August $1^{\text {st }}, 2011$.

\begin{abstract}
Introduction: Breast cancer is a common disease diagnosed in Mexican women and the first leading cause of death [1]. Heterogeneity in patients' response to treatment is consistently observed across populations. Glutathione S-transferases (GSTs) are involved in the metabolism of environmental carcinogens, reactive oxygen species and chemotherapeutic agents by catalyzing the glutathione with electrophilic compounds. The deletion of GSTT1 and GSTM1 genes result in loss of enzyme activity. A few studies evaluated the response to treatment and the polymorphisms of GSTT1 and GSTM1. The aim of this work is to make the association of the null polymorphisms of GSTT1 and GSTM1 with the response to chemotherapy basically doxorubicin and cyclophosphamide. Methods: The genotyping of thirty patients with breast cancer was made with the Polymerase chain reaction, to identify the polymorphisms of GSTT1 and GSTM1. We determine the status of HER-2 neu, estrogen and progesterone receptors, then the response to treatment was made with an ultrasound and pathological data. We made the association with the $\chi i^{2}$ statistics using a $p \leq 0.05$. Results: Using the Sigma Stat 3.5 program and the chi-squared analysis, we do not observe a significant association with the GSTT1+/GSTM1+, GSTT1-/GSTM1+ and GSTT1-/GSTM1-polymorphisms and the better or worse response to cyclophosphamide and doxorubicin. With the HER-2 neu, estrogen and progesterone receptors status, we neither found an association with the response to the therapy. Conclusion: This study suggests that GSTT1 and GSTM1 polymorphisms have no statistical significance between the genotype of women with advanced breast cancer and the response to neoadjuvant chemotherapy, but we can see a clear tendency toward better response with the null genotype.
\end{abstract}

Keywords: Breast Cancer, GSTT1, GSTM1 Polymorphisms, Chemotherapy Response

\section{Introduction}

\subsection{Breast Cancer}

Breast cancer is the most commonly diagnosed cancer in Mexican women and one of the principals leading cause of death, in 2004 represented the $13.3 \%$ of deaths in Mexico, however this pathology shows an increasing tendency over time [1-4]. According to the histopathology register, there were 11,242 new cases in 2002, a higher quantity in comparison with previous years, this means that 50 cases were diagnosed every day, and the most dramatic situation was the advanced stage of diagnosis [5].
Glutathione S-transferase (GST) is a super family of enzymes divided into two distinct groups: the membrane bound microsomal and the cytosolic GSTs, like GSTM1, GSTP1 and GSTT1. It is known that they are crucial for the cell defense system. They are phase II enzymes involved in conjugation of a wide range of xenobiotics [6]. GSTs are induced under conditions of oxidative stress [7], the mechanism of detoxification is by conjugation to reduced glutathione (GSH), a tripeptide consisting of glycine, glutamic acid and cysteine, with electrophilic compounds, reducing the harmful agents to lower toxic levels and water soluble products [8-22].

GSTs exhibit genetic polymorphisms in their popula- 
tion distribution and result in GSTs null phenotypes greatly affect the function of enzymes involved in detoxification of reactive metabolites such as polycyclic aromatic hydrocarbons [23]. Interindividual variation in GST genotype has been related to differences in the occurrence of a number of human malignancies including cancer [12,24-26]. These polymorphisms may predispose population to certain adverse drug reactions or disease occurrence [12]. The evidence shows that GSTs expression plays an important protective effect role on determinating the cytotoxicity of chemotherapeutic drugs [27]. Changes in GSTs levels have been found to correlate with resistance to antineoplastic drugs through accelerated detoxification of the drugs substrates [28].

Heterogeneity in patients' response to chemotherapy is consistently observed across populations and scientists studied several genes which can be related with the individual response for each cytotoxic agent [15, 29].

\subsection{Glutathione S-Transferase $\mathrm{T} 1$}

The GSTT1 gene is located on chromosome 22q11.22, also due to a gene deletion, known as GSTT $1 * 0$ and is non-functional allele $[12,23,30,31]$.

\subsection{Glutathione S-transferase M1}

The GSTM1 gene is located on chromosome 1p13.3. GSTM1 polymorphism and has been identified with three different alleles $(\mathrm{GSTM} 1 * \mathrm{~A}, \mathrm{GSTM} 1 * \mathrm{~B}, \mathrm{GSTM} 1 * 0)$. The homozygous gene deletion is known as GSTM $1 * 0$ and individuals with this genotype are unable to produce the GSTM1 protein. [23,32-36].

Therefore the GSTM1 and GSTT1 null alleles have also been reported to be associated with diminished GST enzyme activity altering response and toxicity from chemotherapy in patients with acute leukemia, breast cancer and metastatic colorectal cancer [15,20,31,37].

The chemotherapy exerts the antineoplastic effect by generating reactive oxygen products (ROS) and by products that are metabolized by different enzymes like GSTT1 and GSTM1 [38]. As those are the proximate cause of tumor cell death in many cases, the amounts of reactive species that reach tumor cells and have either direct cytotoxic effects or trigger intracellular apoptotic pathways is likely to have impact on treatment efficacy. Thus, interindividual variability in enzymes that will affect ROS may have a significant impact in prognosis after treatment [26]. The chemotherapy before surgery has become the standard treatment in local advanced breast cancer and has the capability to reduce the tumor size and the micro metastasis illness

A significant proportion of breast cancer tumors are resistant to chemotherapy agents. As a result, drug resis- tance has become the major cause of chemotherapy failure and is largely responsible for breast cancer mortality $[29,38]$.

The aim of this work is making the association of the null polymorphisms of GSTT1 and GSTM1, the status of HER2, estrogen and progesterone receptors with the response to chemotherapy, specific the treatment with doxorubicin associated to cyclophosphamide in Mexican women with advanced breast cancer.

\section{Material and Methods}

\subsection{Population Characteristics}

This study was submitted and approved bye the Centro Oncológico Estatal ISSEMyM Ethics Committee, giving the protocol number COE/CCBI-036.

The subjects of this research were thirty women diagnosed with advanced breast cancer documented by biopsy, in stage IIB, IIIA or IIIB, virgins to treatment attended in Centro Oncológico Estatal ISSEMyM $(n=18)$ and the Hospital de la Mujer SSA of D.F. $(n=12)$ which needed a neoadjuvant therapy based in doxorubicin associated to cyclophosphamide. These women signed an informed consent form to allow us to identify genes from peripheral blood and identify the status of Her2-neu, estrogen and progesterone receptors.

Tumors were characterized before treatment by the clinical size, and TNM characteristics. All patients underwent an ultrasound to determine the size and location of tumor. A second ultrasound was made when the patients finalized the therapy to evaluate the chemotherapy response.

All the procedures were made according to the declaration of Helsinki [39].

\subsection{Chemotherapy Regimen Description}

All patients with the same conditions received the standard treatment that consisted in a premedication of granisetron $1 \mathrm{mg}$, dexamethasone $16 \mathrm{mg}$ and ranitidine $50 \mathrm{mg}$. After these, an infusion of doxorubicin $60 \mathrm{mg} / \mathrm{m}^{2}$ diluted in $250 \mathrm{~mL}$ of glucose solution was administrated in 60 minutes, then a solution of cyclophosphamide $600 \mathrm{mg} / \mathrm{m}^{2}$ diluted in $500 \mathrm{~mL}$ of saline solution $0.9 \%$ was administrated during 60 minutes. This cycle was administrated four times every twenty one days.

\subsection{Genotyping}

Sample: 3 or $4 \mathrm{~mL}$ of venous blood was taken by vacutainer tube with $7.2 \mathrm{mg}$ of EDTA.

DNA extraction: the DNA was extracted, according to the manufacturers recommendations for blood sample, by using the Zymo ZR Genomic DNA II Kit. 
Polymerase chain reaction method: GSTT1 and GSTM1 genotyping were performed by a multiplex PCR Abdel-Rahman's assay [40] improved for our laboratory, with conditions of initial denaturalization of $94^{\circ} \mathrm{C}, 5$ minutes; denaturalization $94^{\circ} \mathrm{C}, 45$ seconds; alignment $55^{\circ} \mathrm{C}, 45$ seconds; extension $72^{\circ} \mathrm{C}, 45$ seconds and final extension $72^{\circ} \mathrm{C}, 5$ minutes, by 35 cycles. With a horizontal electrophoresis in $2 \%$ agarose we can see the presence of a $480 \mathrm{pb}$ and a $215 \mathrm{pb}$ bands corresponding to GSTT1 and GSTM1 respectively, and a band of $320 \mathrm{pb}$ corresponding to CYP1A1 co-amplified in the assay and used as an internal control. The absence of the bands of GSTM1 or GSTT1 indicated the null polymorphisms of these genes.

The sequence of the primer GSTT1 forward was 5'-TCA CCG GAT CAT GGC CAG CA-3' and reverse 5'-TTC CTT ACT GGT CCT CAC ATC TC -3', GSTM1 forward was 5'-GAA CTC CCT GAA AAG CTA AAG C-3 and reverse 5'-GTT GGG CTC AAA TAT ACG GTG G-3', CYP1A1 forward was 5'-GTT GGG CTC AAA TAT ACG GTG G-3' and reverse was 5'-CAG CTG CAT TTG GAA GTG CTC-3' (Sigma) $[29,23,40]$.

\subsection{Classification of Response to Chemotherapy}

The decrease in the tumor size was measured by the RECIST criteria consisting in taking an ultrasound of the affected breast before and after the treatment and classifying it in complete response (CR), when the second ultrasound shows no evidence of tumor, partial response (PR), when the second ultrasound showed a tumor diminished $\geq 50 \%$ in comparison with the first, and no response (NR), when the ultrasound showed no changes or grow in the tumor, despite of the chemotherapy [41].

Routinely we made the immunohistochemistry for the determination of the estrogens, progesterone and HER-2 neu receptors, with the aim of establish if the tumor has molecular characteristics, which can deprecate in the illness.

\subsection{Statistical Analysis}

Differences between categorical variables were measured by the $\chi^{2}$ co-relation test between the treatment response and the polymorphisms of GSTT1 and GSTM1 using the statistical program Sigma Stats 3.5. The results were considered statistically significant when $p$ values were $\leq 0.05$.

\section{Results}

\subsection{Clinicopathological Data}

The median age of patients $(n=30)$ was 47.96 years, range 33 - 75. All samples were of women with infiltrat- ing ductal carcinoma of breast cancer, corresponded of IIB, IIIA and IIIB stages.

\subsection{GSTM1 and GSTT1 Genotype Determination and Response to Neoadjuvant Therapy}

We were interested in the isolated and combined effects of each gene with the clinical response. With the genotype GSTT1+ our findings were $53.84 \%$ of the participants with no response, $23.07 \%$ with partial and $23.07 \%$ with complete. With the GSTT1- genotype we observed $41.17 \%$ with no response; $41.17 \%$ with partial and $17.64 \%$ with complete. We observed with the genotype GSTM1+, $52.38 \%$ with no response, $28.57 \%$ with partial and $19.04 \%$ with complete. With GSTM1-33.33\% with no response, $44.44 \%$ with partial and $22.22 \%$ with complete (Table 1). Analyzing the patients with the presence of both genes, GSTT1+/GSTM1+, $61.52 \%$ showed no response, $15.37 \%$ partial responses and $23.05 \%$ showed complete clinical response. With both null genes GSTT1-/GSTM1+, 50\% showed no response, 37.47\% partial responses and $12.49 \%$ complete responses, with GSTT1-/GSTM1- 33.33\% showed no response, $44.44 \%$ partial responses and $22.22 \%$ complete response. The $\chi^{2}$ analysis, with a $p \leq 0.05$, we do not observed a statistically significant association with the isolated genes (Table 1) and the GSTT1+/GSTM1+, GSTT1-/GSTM1+ and GSTT1-/GSTM1- polymorphisms and the better or worse response to cyclophosphamide and doxorubicin (Table 2). However, we note a tendency toward better response from women possessing at least one gene with the null form.

In this study we found that $31.25 \%$ had the HER2neu(+), and $68.75 \%(-)$. A $6.25 \%$ of the patients with HER2 (+) had complete response, a $12.5 \%$ had partial response and a $12.5 \%$ showed no response. With the receptor HER2(-) A $18.75 \%$ had a complete response, a $12.5 \%$ a partial and a $37.5 \%$ a no response. The statistical analysis showed that this variable is not related with the response to the treatment with a $p=0.873$ (Table 3).

With regard to estrogen receptors, it has been reported that tumors with overexpression of them, do not response to conventional chemotherapy. It has also been shown that tumors with lack of these receptors have more complete pathological responses. In our study we found a $56.25 \%$ of women with $\mathrm{RE}(+), 18.75 \%$ of them showed a complete response and $6.25 \%$ a partial response and $31.25 \%$ a no response. According to the RE(-), 6.25\% had a complete response, $18.75 \%$ a partial and $18.75 \%$ a no response. With these results we confirm the behavior, founding increase partial responses with negative estrogen receptors, than women who showed an overexpres- 
Table 1. Response to treatment according with each isolated gene.

\begin{tabular}{cccc}
\hline & Complete & Partial & No response \\
\hline GSTT1+ & 23.07 & 23.07 & 53.84 \\
GSTT1- & 17.64 & 41.17 & 41.17 \\
GSTM1+ & 19.04 & 33.33 & 52.38 \\
GSTM1- & 22.22 & 44.44 & 33.33 \\
\hline$\chi^{2}, p=0.607$. & & &
\end{tabular}

Table 2. Response to treatment according with the complete genotype.

\begin{tabular}{cccc}
\hline & GSTT1+/ & GSTT1-/ & GSTT1-/ \\
GSTM1+ & GSTM1+ & GSTM1- \\
\hline Complete & 23.05 & 12.49 & 22.22 \\
Partial & 15.37 & 37.47 & 44.44 \\
No & 61.52 & 50 & 33.33 \\
response & & & \\
$\chi^{2}, p=0.188$. & & &
\end{tabular}

Table 3. Response to treatment according with the HER2neu, estrogens and progesterone receptors status.

\begin{tabular}{cccc}
\hline & Complete & Partial & No response \\
\hline HER2-neu(+) & 6.25 & 12.5 & 12.5 \\
Her2-neu(-) & 18.75 & 12.5 & 37.5 \\
Estrogen(+) & 18.75 & 6.25 & 31.25 \\
Estrogen(-) & 6.25 & 18.75 & 18.75 \\
Progesterone(+) & 18.75 & 6.25 & 37.5 \\
Progesterone(-) & 6.25 & 18.75 & 12.5 \\
\hline$\chi^{2}, p=0.382$ & & &
\end{tabular}

sion of them. The correlation analysis, showed no statistical significance of $\chi^{2}$ (Table 3).

Taking the variable progesterone receptors, we observed a $18.75 \%$ with complete response, $6.25 \%$ with partial response and $37.5 \%$ with no response of women whom possessed the overexpression $\mathrm{PR}(+)$. Women with $\mathrm{PR}(-), 6.25 \%$ showed complete response, $18.75 \%$ partial response and $12.5 \%$ no response. The correlation analysis showed no statistical significance of $\chi^{2}$ (Table 3 ).

\section{Discussion}

The evidence suggests that the null polymorphisms of GSTT1 and GSTM1 can increment the level of DNA damage and increase the susceptibility to breast cancer because of the low capacity of detoxify xenobiotics such as aromatic compounds [29].

In the case of breast cancer, a wide proportion of tumors in advanced stages is resistant to antineoplastic agents and this is responsible of death and adverse events $[20,41,42]$.
Neoadjuvant therapy is the standard treatment of advanced breast cancer, because it allows the increased conservative surgery, to measure the response and study of the new biomarkers, which could help to meet the apoptosis and response mechanisms [38].

Several studies have demonstrated the association of null polymorphisms of GSTT1, GTM1 and GSTP1 and the risk of different kind of cancers including breast cancer $[17,31,35,36]$ but there are few studies that evaluated the side effects related to these polymorphisms as we can see in Davis et al. study $(n=306)$, they established that the null genotype of GSTT1 is related with increase therapy toxicity in patients with acute leukemia [27]. Kelly et al. showed that null polymorphisms are associated with increased risk of development cancer and complications in leukemia and mielodisplasic syndrome treatment [33]. These results can be related with the drug dose with increased dose the null genotype cannot detoxify the therapeutic agents producing adverse effects and death like in ovarian cancer and leukemia treatment [27,33], and with less dose, like in breast cancer therapy, the null genotypes increased the efficacy.

Other studies evaluate the response to treatment and the polymorphisms. Between the studies we have of Howells et al. $(n=148)$, found that there was no effect for this isolated genes, but the combined null genotype were associated with a poor survival in women with ovarian cancer [43].

Ambrosone et al. $(n=251)$, published that the null polymorphisms of these genes and particularly, the combined deletion of both genes significantly reduced hazard of death among women who received treatment for breast cancer. Women who were null for either GSTM1 or GSTT1 had half the hazard of death than those with at least one allele and in comparison with those with both genes present, women with both null genotype had one-third the risk of death following treatment. In summary null genotypes give a better response to the therapy versus women that have the genes present who detoxify antineoplastic agents and reduce treatment efficacy [29].

The study of Kedhaier et al. $(n=309)$, showed a borderline significant increase in the risk of primary breast cancer in unselected subjects carrying null GSTT1 polymorphisms [26]. In other study $(n=314)$ they evaluated the clinical response with chemotherapy and the polymorphisms between GSTT1 and GSTM1 gene deletion. This evaluation indicated that only GSTT1 gene deletion is associated with the clinical response to chemotherapy. Although no significant association was found between GSTM1 gene deletion and the response. The better response to chemotherapy was observed among GSTT1 null patients, who were no treated with 
high dose therapy, and it will be a susceptibility and prognostic of chemotherapy biological marker [17].

According to the results of the studios of Lizard-Nacol et al. $(n=92)$, they demonstrated that the GSTM1 null genotype did not differ in the breast cancer therapy response from those with GSTM1 positive genotype. Thus, individuals carrying the GSTM1+ polymorphism were no more resistant to chemotherapy than those with GSTM1- genotype [44].

Gor et al. $(n=350)$, made a relation with the genotype GSTT1 and GSTM1 and the combined genotype of both and survival with a treatment based on cyclophosphamide and anthracyclines. They found that null genotype of GSTT1 with the SNP CYP3A4*IA had better disease free survival and overall survival [45].

In the present study we try to determine a relation between the null polymorphisms of GSTT1 and GSTM1 and the chemotherapy response with doxorubicin and cyclophosphamide, affecting the pathologic response to antineoplastic drugs.

In patients with genotype GSTT1+/GSTM1+, as in the wild genes analyzed separately, shows a strong tendency to non-responders. This is consistent because both enzymes have greater capacity to detoxify the drugs used in chemotherapy. If we examine the response of the genotype GSTT1-/GSTM1+, we can see that half of the study population did not respond to treatment, a fact that we can correlate with previous reports which stated that the enzyme GSTM1 has a protective effect against anthracyclines and alkylating agents as in the case of cyclophosphamide. In the case of genotype GSTT1-/GST- there is a higher percentage of women with cancer had a partial response, this may be due to a lack of chemotherapy cycles.

An interesting fact to note is not found combined genotype of GSTT+/GSTM1-, that we might suggest that within the population of the State of Mexico. Is not common this genotype, is important to note that there are few studies showing the frequency of this genotype in Mexican mestizo population, however, Perez et al. (2006) reported a frequency of $11.3 \%$ [46], so really do not know if this frequency is too low or if a genotype with characteristics that may influence not to have this tumor.

Our findings do not support any statistical association with the polymorphisms and the treatment response; however, the small amount of our population $(n=30)$ may have a little power to detect any association of genotype-response, however, we note a tendency toward better response from women who possessed at least one null gene.

Another aspect that could affect our statistical significance of the data is that we may have missed some ef- fects as the multidrug resistance conferred by over, low and no expression of GSTT1 and GSTM1 polymorphisms (GSTT1*A, GSTT1*B, GSTT*0, GSTM1*A, GSTM $1 *$ B and GSTM $1 * 0$ ), because our genotyping assay could not distinguish between wild type and the other existent polymorphisms. These have a great importance, because it is known that individuals carried the null polymorphism are unable to metabolize different kinds of xenobiotic like the combined chemotherapy with doxorubicin and cyclophosphamide. On the other hand, we have individuals with another kind of polymorphism $($ GSTT $1 *$ B and GSTTM $1 *$ B) whose detoxifying enzyme activity will be decreased significantly from the wild type [36].

We emphasize that the study in humans, is complex because we must take into account interactions with other concomitant drugs, diet, pollution and endogenous substances that can create adverse reactions or can interfere with chemotherapy, as in the case of cyclophosphamide is a prodrug and must be biotransformed to carry out their biological action of cytotoxicity, and whether there are other drugs that use the same enzymes in the metabolism and can cause the final amount of ifosfamide metabolites and nitrogen mustard that cause action are reduced.

Regarding the status of Her2-neu, we found that overexpression implies a poor prognosis, however patients with this property show high sensitivity to neoadjuvant chemotherapy based on anthracyclines and taxanes, finding complete pathological response [48]. In our project could not verify this, as there was no trend, probably due to the number of cases that were classified with the this biomarker.

With regard to estrogen receptors has been reported that tumors with overexpression of them unresponsive to conventional chemotherapy. It also has been shown that tumors with ER(-) have more complete pathological responses to neoadjuvant chemotherapy than the $\mathrm{R}(+)$ [47]. In our study we confirm this behavior, because we found an increase in partial responses in patients with $\operatorname{ER}(-)$, compared with women who showed ER(+).

The molecular classification may be more powerful than the histopathology, as a predictor of response tendency. The identification of genetic factors as GSTT1 and GSTM1, may be done in the future, improving the treatment and reducing the side effects with more selective chemotherapy.

\section{Conclusions}

In summary, this study do not support that GSTT1 and GSTM1 genes have statistical significance between the genotype of women with advanced breast cancer and the 
response to neoadjuvant chemotherapy with doxorubicin and cyclophosphamide, but we can see a clear tendency to better response with the null genes.

Larger epidemiological studies are required to clarify the relationship between the role of GST's polymorphisms and the individual pathologic response to neoadjuvant chemotherapy with the final objective of the use of these genes as potential response biomarker predictors for breast cancer treatment outcomes with antineoplastic drugs.

\section{List of Abbreviations}

ER: Estrogen receptors

HER2-neu:

GST: Glutathione S-transferase

GSTM1: Glutathione S-transferase mu 1

GSTT1: Glutathione S-transferase theta 1

ROS: Reactive oxygen products

pb: pair of bases

PCR: Polymerase chain reaction

PR: Progesterone receptors

\section{Competing Interests}

There are non-financial competing interests in this study.

\section{Acknowledgements}

To Dr. Alberto Hardy Perez, the pathologists Dr. Eduardo Gómez Plata, Dr. César Lara and Dr. David Aguirre, and to the oncologist surgeons Dr. Rodrigo Serrano and Dr. García Millán from Centro Oncológico Estatal ISSEMyM for they contribution in this study.

\section{REFERENCES}

[1] SINAIS, "Sistema Nacional de Información en Salud. Gobierno Federal, Noviembre 2008," 2010. http://sinais.salud.gob.mx/mortalidad

[2] N. Garcia, F. Salamanca, H. Astudillo de la Vega, E. Curiel-QueSada, I. Alvarado, R. Peñaloza and D. Arenas, "A Molecular Analysis by Gene Expression Profiling Reveals Bik/NBK over expression in Sporadic Breast Tumor Samples of Mexican Females," BMC Cancer, Vol. 5, 2005, pp. 93-104. doi:10.1186/1471-2407-5-93

[3] L. Jorde, J. Carey and M. Bamshad, "Genética Médica," 2nd Edition, Harcourt, Madrid, 2000.

[4] M. E. Brandan and Y. Villasenor, "Detección del Cáncer de Mama: Estado de la Mamografía en México," Cancerologia, Vol. 1, No. 6, 2006, pp. 147-162.

[5] S. A. Rodríguez Cuevas, F. Guisa-Hohenstein, S. Labastida-Almendaro, R. Espejo-Fonseca, et al., "Resultados del Primer Programa de Detección Oportuna de Cáncer de Mama en México Mediante Pesquisa Conmastografía," Gaceta Mexicana de Oncología, Vol. 8, No. 3, 2009, pp. 83-95.
[6] Z. Ye and H. Song, "Glutathione s-Transferase Polymorphisms (GSTM1, GSTP1 and GSTT1 and the Risk of Acute Leukaemia: A Systematic Review and Meta Analysis," European Journal of Cancer, Vol. 41, No. 7, 2005, pp. 980-989. doi:10.1016/j.ejca.2005.01.014

[7] M. Gago-Domínguez, X. Jiang and J. E. Castelao, "Lipid Peroxidation, Oxidative Stress Genes and Dietary Factors in Breast Cancer Protection: A Hypothesis," Breast Cancer Research, Vol. 9, No. 1, p. 201.

[8] C. Kiyohara, "Genetic Polymorphism of Enzymes Involved in Xenobiotic Metabolism and the Risk of Colorectal Cancer," Journal of Epidemiology, Vol. 10. No. 5, 2000, pp. 349-360.

[9] D. Sheehan, G. Meade, V. Foley and C. A. Dowd, "Structure, Function and Evolution of Glutathione Transferases: Implications for Classification of Non-mammalian Members of an Ancient Enzyme Superfamily," Biochemical Journal, Vol. 360, 2001, pp. 1-16. doi:10.1042/0264-6021:3600001

[10] J. M. Allan, C. P. Wild, S. Rollinson, E. V. Willett, A. V. Moorman, G. J. Dovey, P. L. Roddam, E. Roman, R. A. Carthwright and G. J. Morgan, "Polymorphisms in Glutathione S-Transferase P1 is Associated with Susceptibility to Chemotherapy Induced Leukemia," Proceeding of the National Academy of Sciences of the United States of America, Vol. 98, No. 20, 2001, pp. 11592-11597.

[11] V. R. Arruda, C. S. Lima, C. R. Grignoli, M. B. de Melo, I. Lorand-Metze, F. L. Alberto, S. T. Saad and F. F. Costa, "Increased RISK for Acute Myeloid Leukaemia in Individuals with Glutathione S-Transferase mu1 (GSTM1) and Teta 1 (GSTT1) Gene Defects," European Journal of Haematology, Vol. 66, No. 6, 2001, pp. 383-388. doi:10.1034/j.1600-0609.2001.066006383.x

[12] A. Rossini, D. C. Rapozo, L. M. Amorim, J. M. Macedo, R. Medina, J. F. Neto, C. V. Gallo and L. F. Pinto, "Frequencies of GSTM1, GSTT1, and GSTP1 Polymorphisms in Brazilian Population," Genetics and Molecular Research, Vol. 1, No. 3, 2002, pp. 233-240.

[13] D. M. Townsend and K. D. Tew, "The Role of Glutathione-S-Transferase in Anticancer Drug Resistance," Oncogene, Vol. 22, 2003, pp. 7369-7377. doi.org/10.1038/sj.onc. 1206940

[14] M. Aydin-Sayitoglu, O. Hatirnaz, N. Erensoy and U. Ozbek, "Role of CYP2D6, CYP1A1, CYP2E1, GSTT1, and GSTM1 Genes in the Susceptibility to Acute Leukemias," American Journal of Hematology, Vol. 81, 2006, pp. 162-170.

[15] G. I. Mossallam, T. M. Abdel Hamid and M. A. Samra, "Gluthation S-transferase GSTM1 and GSTT1 Polymorphisms in Adult Acute Myeloid Leukemia, Its Impact on Toxicity and Response to Chemotherapy," Journal of Egypt National Cancer Institution, Vol. 18, No. 3, 2006, pp. 264-273.

[16] M. Reis, "Farmacogenética Aplicada al Cáncer: Quimioterapia Individualizada y Especificidad Molecular en Medicina," Revista Médica de Chile, Vol. 39, No. 4, 2006, pp. 577-586. 
[17] A. Khedhaier, E. Hassen, N. Bouaouina, S. Gabbou, J. S. B. Ahmed and L. Chouchane, "Implication of Xenobiotics Metabolizing Enzime Gene (CYP2E1, CYP2C19, CYP2D6, $\mathrm{mEH}$ and NAT2) Polymorphisms in Breast Cancer," BMC Cancer, Vol. 8, 2008, p. 109.

[18] F. Skjelbred, M. Sæbø, A. Hjartåker, T. Grotmol, I. L. Hansteen, K. M. Tveit, G. Hoff and E. H. Kure, "Meat, Vegetables and Genetic Polymorphisms and the Risk of Colorectal Carcinomas and Adenomas," BMC Cancer, Vol. 7. 2007, p. 228.

[19] P. Bolufer, M. Collado, E. Barragan, M. J. Calasanz, D. Colomer, M. Tormo, M. Gonzalez, S. Brunet, M. Batlle, J. Cervera and M. A. Sanz, "Profile of Polymorphisms of Drug-Metabolising Enzymes and the Risk of TherapyRelated Leukemia," British Journal of Haematology, Vol. 136, No. 4, 2006, pp. 590-596. doi:10.1111/j.1365-2141.2006.06469.x

[20] E. Goekkurt, S. Hoehn, C. Wolschke, C. Wittmer, C. Stueber, D. K. Hossfeld and J. Stoehlmacher, "Polymorphisms of Glutathione S-Transferases (GST) and Thymydilate Synthase (TS) Novel Predictors for Response and Survival in Gastric Cancer Patients," British Journal of Cancer, Vol. 94, No. 2, 2006, pp. 281-286. doi:10.1038/sj.bjc. 6602891

[21] P. Depeille, P. Cuq, I. Passagne, A. Evrard and L. Vian, "Combined Effects of GSTP1 and MRP1 in Melanoma Drug Resistance," British Journal of Cancer, Vol. 93, 2005, pp. 216-223. doi:10.1038/sj.bjc.6602681

[22] L. M. Dong, J. D. Potter, E. White, C. M. Ulrich, L. R. Cardon and U. Peters, "Genetic Susceptibility to Cancer. Role of Polymorphisms in Candidate Genes," The Journal of American Medical Association, Vol. 299, No. 20, 2008, pp. 2423-2436. doi.org/10.1001/jama.299.20.2423

[23] T. Pongtheerat, M. Treetrisool and W. Purisa, "Glutathion S-Transferase Polymorphisms in Breast Cancers of Thai Patients," Asian Pacific Journal of Cancer Review, Vol. 10. No. 1, 2009, pp. 127-132.

[24] M. H. Woo, J. J. Shuster, C. Chen, R. O. Bash, F. G. Behm, B. Camitta, C. A. Felix, B. A. Kamen, C. H. Pui, S C. Raimondi, N. J. Winick, M. D. Amylon and M. V. Relling, "Glutathione S-Transferase Genotypes in Children Who Develop Treatment Related Acute Myeloid Malignancies," Leukemia, Vol. 14, No. 2, 2000, pp. 232237. doi:10.1038/sj.leu.2401660

[25] A. Buchard, J. J. Sánchez, K. Dalhoff and N. Morling, "Multiplex PCR Detection of GSTM1, GSTT1 and GSTP1 Gene Variants," The Journal of Molecular Diagnostics, Vol. 9, No. 5, 2007, pp. 612-617. doi:10.2353/jmoldx.2007.070030

[26] A. Khedhaier, S. Remadi, M. Corbex, S. B. Ahmed, N. Bouaouina, S. Mestiri, R. Azaiez, A. N. Helal and L. Chouchane, "Glutathione S-Transferases (GSTT1 and GSTM1) Gene Deletions in Tunisians: Susceptibility and Prognostic Implications in Breast Carcinoma," British Journal of Cancer, Vol. 89, 2003, pp. 1502-1507. doi:10.1038/sj.bjc. 6601292

[27] S. M. Davies, L. L. Robison, J. D. Bucley, T. Tjoa, W. G.
Woods, G. A. Radloff, J. A. Ross and J. P. Parenthesis, "Glutation S-Transferase Polymorphisms and Outcome of Chemotherapy in Childhood Acute Myeloid Leukemia," Journal of Clinic Oncology, Vol. 19, 2001, pp. 12791287.

[28] T. Naoe, K. Takeyama, T. Yokozawa, H. Kiyoi, et al., "Analysis of Genetic Polymorphism in NQ01, GSTM-1, GST-T1, and CYP3A4 in 469 Japanese Patients with Therapy-Related Leukemia Mielodysplasic Syndrome and de Novo Acute Myeloid Leukemia," Clinical Cancer Research, Vol. 6, No. 10, 2000, pp. 4091-4095.

[29] B. Ambrosone, C. Sweeney, B. F. Coles, P. A. Thompson, G. Y. McClure, S. Korourian, M. Y. Fares, A. Stone, F. F. Kadlubar and L. F. Hutchins, "Polymorphisms in Glutathione S-Transferase (GSTM1 and GSTT1) and Survival after Treatment for Breast Cancer," Cancer Research, Vol. 61, 2001, pp. 7130-7135.

[30] A. Hiroven, "Polymorphisms of Xenobiotic Metabolizing Enzymes and Susceptibility to Cancer," Environmental Health Perspectives, Vol. 107, No. 1, 1999, pp. 37-47.

[31] W. W. Au, H. Y. Oh, J. Grady, S. A. Salama and M. Y. Heo, "Usefulness of Genetic Susceptibility and Biomarkers for Evaluation of Environmental Health Risk," Environmental and Molecular Mutagenesis, Vol. 37, No. 3, 2001, pp. 215-225. doi:10.1002/em.1030

[32] M. Saadat, "Genetic Polymorphisms of Glutathione S-Transferase T1 (GSTT1) and Susceptibility to Gastric Cancer: A Meta-Analysis," Cancer Science, Vol. 97, No. 6, 2006, pp. 505-509.

[33] K. M. Kelly and J. P. Perentesis, "Polymorphisms of Drug Metabolizing Enzymes and Markers of Genotoxicity to Identify Patients with Hodgkin's Lymphoma at Risk of Treatment-Related Complications," Annals of Oncology, Vol. 13, No. 1, 2002, pp. 34-39.

[34] D. Sheenan, G. Meade, V. M. Foley and C. A. Dowd, "Structure, Function and Evolution of Glutathione Transferases: Implications for CLassification of Non-Mammalian Members of an Ancient Enzyme Superfamily," Biochemical Journal, Vol. 360, 2001, pp. 1-16. doi:10.1042/0264-6021:3600001

[35] L. Jiao, M. L. Bondy, M. M. Hassan, D. Z. Chang, J. L. Abbruzzese, D. B. Evans, M. H. Smolensky and D. Li, "Glutathione S-Transferase Gene Polymorphism and Risk and Survival of Pancreatic Cancer," Cancer, Vol. 109, No. 5, 2007, pp. 840-848. doi:10.1002/cncr.22468

[36] M. Habdous, G. Siest, B. Herbeth, M. Vicent-Viry and S. Visvikis, "Polymorphismes des Glutathionne S-Transférases et Pathologies Humaines: Bilan des Études Épidémiologiques," Annals of Biology, Vol. 62, 2004, pp. 15-24.

[37] Valladares, N. García Hernández, F. Salamanca Gómez, E. Curiel Quesada, E. Madrigal Bujaidar, M. D. Vergara, M. Sierra Martinez and D. Arenas Arana, "Genetic Expression Profiles and ChromoSomal Alterations in Sporadic Breast Cáncer in Mexican Women," Cancer Genetics and Cytogenetics, Vol. 170, No. 2, 2006, pp. 147-151. doi:10.1016/j.cancergencyto.2006.06.002 
[38] A. Insan, I. Chirivella and A. Llunch, "Tratamiento Neoadyuvante del Cáncer de Mama Operable," Medicine Clinic, Vol. 126, No. 8, 2006, pp. 295-303.

[39] Apendice F. Declaracion de Helsinki. [http://www.inb.unam.mx/bioetica/documentos/declaraci on_helsinki.pdf].

[40] S. Z. Abdel-Rahman, R. A. El-Zein, W. A. Anwar, et al., "A multiplex PCR Procedure for Polymorphic Analysis of GSTM1 and GSTT1 Genes in Population Studies," Cancer Letters, Vol. 107, No. 2, 1996, pp. 229-233. doi:10.1016/0304-3835(96)04832-X

[41] G. van der Zee, B. van Ommen, C. Meijer, H. Hollema, P. J. van Bladeren and E. G. de Vries, "Glutathione S-Transferase Activity and Isoenzyme Composition in Benign Ovarian TUmurs, Untreated Malignant Ovarian Tumours, and Malignant Ovarian Tumours after Platinum/Cyclophosphamide Chemotherapy," British Journal of Cancer, Vol. 66, No. 5, 1992, pp. 930-936. doi:10.1038/bjc. 1992.388

[42] S. Zhong, M. Huang, X. Yang, L. Liang, Y. Wang, M. Romkes, W. Duan, E. Chan and S. F. Zhou, "Relationship of Glutathione S-Transferase Genotypes with Side-Effects of Pulsed Cyclophosphamide Therapy in Patients with Systemic Lupus Erythematosus," British Journal of Clinical Pharmacology, Vol. 62, No. 4, 2006, pp. 457-472. doi:10.1111/j.1365-2125.2006.02690.x

[43] Howells, C. W. Redman, K. K. Dhar, P. Sarhanis, C.
Musgrove, P. W. Jones, J. Alldersea, A. A. Fryer, P. R. Hoban and R. C. Strange, "Association of Glutathione S-Transferase GSTM1 and GSTT1 Null Genotypes with Clinical Outcome in Epithelial Ovarian Cancer," Clinical Cancer Research, Vol. 4, No. 10, 1998, pp. 2439-2445.

[44] S. Lizard Nacol, B. Coudert, P. Colosetti, J. M. Riedinger, P. Fargeot and P. Brunet-Lecomte, "Glutathione STransferse M1 Null Genotype: Lack of Association with Tumor Characteristics and Survival Advanced Breast Cancer," Breast Cancer Research, Vol. 1, No. 1, pp. 8187. doi:10.1186/bcr17

[45] P. P. Gor, H. I. Su, R. J. Gray, P. A. Gimotty, M. Horn, R. Aplenc, W. P. Vaughan, M. S. Tallman, T. R. Rebbeck and A. DeMichele, "CyclophosPhamide-Metabolizing Enzyme Polymorphisms and Survival Outcomes after Adjuvant Chemotherapy for Node-Positive Breast Cancer: A Retrospective Cohort Study," Breast Cancer Research, Vol. 12, 2010. doi:10.1186/bcr2570

[46] R. Pérez, C. Castro, M. E. Gonsebatt and J. Rubio, "Polymorphisms of CYP1A1*2C, GSTM1*0 and GSTT1*0 in Mexican Mestizo Population: A Similitude Analysis," Human Biology, Vol. 80, No. 4, 2008, pp. 457-465.

[47] J. Zapata Castilla, E. Recinos Money, M. Cuéllar Hubbe, C. D. Robles Vidal and E. Maafs Molina, "Clasificación Molecular del Cáncer de Mama,” Cir Ciruj, Vol. 76, 2008, pp. 87-93. 